\title{
Case Study of Program Management in Canada
}

\author{
Dr. Liza Heslop \\ Centre for Health Services Operations Management \\ Faculty of Medicine, Nursing and Health Sciences \\ Faculty of Information Technology \\ Monash University \\ Victoria, Australia \\ Dr. Karen Francis \\ Professor Rural Nursing \\ Faculty of Medicine, Nursing and Health Sciences \\ Monash University \\ Victoria, Australia
}

\section{Abstract}

This study explored the central concepts, themes and development of program management within the organizational context of public health services delivery in Canada in the late 1990s. Interviews with seven key officials involved in the design and development of program management in two Canadian health services organizations were transcribed and analyzed to gain an understanding of evolving strategies and practices. Thematic analysis revealed a complex interplay of institutional, professional and disciplinary processes and tensions that these officials attributed to the changing organizational configurations of program management. Interpretation of the opinions and decisions taken by these healthcare managers and senior nurses illustrates the strategic and operational response of two Canadian health services organizations to economic reform.

This study explored the ways in which seven Canadian healthcare officials in two organizations negotiated, interpreted and implemented recent changes to their system of care delivery in the late 1990s. The description and discussion that follow illuminate the evolution of the understandings, strategies and practices that accomplished program management in their organizations. 
In this paper, "program management" refers to a management approach, typically arising within a rapidly changing organizational context, that involves the structural regrouping of staff according to patient care "programs" (Hibberd and Smith 1999: 136-39; Bryan 1996). Commencing in the early 1990s, political and financial pressures required Canadian provincial governments to implement measures of economic reform (Hibberd and Smith 1999). For healthcare organizations, these measures resulted in a period of "downsizing," or closure of acute hospital beds, as provinces strove to improve coordination and reduce the costs of healthcare delivery within specific geographical or health regions (Kieser and Wilson 1995: 87). Officials in two large Canadian public health services organizations were managing change at this time under the new program structure. They agreed to participate in this study to show the trends, issues and challenges that evolved in their conceptualization and implementation of program management.

\section{Study Design}

The authors used a case studies approach (Yin 1998; Brink and Wood 1998; Stake 2002) to examine the conceptualization and implementation of program management in two large Canadian health facilities. In-depth interviews were conducted with senior health services professionals ("officials") who agreed to participate across two urban sites that form part of the public healthcare sector for one Canadian province. The interviews, which were undertaken in the late 1990s, were audiotaped and subsequently transcribed. The transcriptions were then reviewed and subjected to thematic analysis. Significant statements and phrases were extracted from the text that explicated the processes adopted and their impact on those involved (Roberts and Taylor 2002; Schneider et al. 2003).

The officials who agreed to participate included IP and HA (practice consultants), LD (senior executive), BT (senior executive), CJ (senior executive), YP (program director) and VP (most senior executive), all of whom had a nursing background. These officials held senior managerial positions in public office and worked in a public capacity. They represented some of the key organizational players from health services organizations and were knowledge experts involved in local and provincial healthcare reform.

At the time that data were collected, Canadian healthcare organizations had considerable recent experience of restructuring (Hibberd and Smith 1999). From the early 1990s, the management of healthcare expenditure was characterized by cost containment, capping of clinical services, downsizing and consolidation of activities and restructuring of work design (Shortell and Kaluzny 2000). While these measures extended across different sectors of healthcare provision ranging from acute (institutional) to community care, the analysis presented in this paper focuses on the impact on acute healthcare services. 
During the interviews, participants' subjective views were explored about the impact of healthcare reform on models of care and new approaches to clinical operations. The impact of economic reform on nursing staff and patient care delivery systems was also explicated. The findings reported include details of the officials' recommendations for reform, the approaches adopted by their organizations, the outcomes achieved and the implications for their health teams.

\section{Restructuring Clinical Operations to Form Program Management}

Each official described changes in healthcare delivery and the resultant methods of implementation employed in his or her program locale. Program management essentially involved restructuring traditional departments within health services organizations (Hibberd and Smith 1999) such that clinical departments were transformed into patient-based care units. (For this reason, this management approach is sometimes called patient-based management.)

Program management reorganizes care delivery around groups of patients with like needs (for example, maternal, child, surgical, medical or mental health) (Hibberd and Smith 1999). The patient base can be as small as a 90-bed hospital with five or six programs, or it can be large. In a large hospital, a program may encompass five or six units of patients. A small hospital might have only 10 patients in a program or 10 beds. Every program varies, depending on the size of the organization and the process by which it determines programs appropriate to its client base (Hibberd and Smith 1999).

Program management eliminates traditional hospital departments. Each program is co-led by a medical director and a patient services director (often a nurse with a master's degree) (Hibberd and Smith 1999). LD placed much importance on retaining nurse managers as patient services directors, so that the nursing and medical managers were directing the program on an equal level:

... that one was a very long and very hard fight. Yeah, that was a big coup! We're pleased with that. It's been a year of growing pains! But I think the final evaluation of this past year will be somewhat positive. The goal was to be more proactive to changing demands and all such things. And to be quite honest if I look back and I know the scope there, so if I look back I think we were reactive to changing things and in changing demands.

In the program restructuring introduced in 1996, the work of traditional disciplinespecific departments was reconfigured into integrated professional structures so that multidisciplinary teams could interact in revised programs in ways not previously required or practised (Homes 2003). According to CJ, a professional advisory committee was created in 1996 to facilitate this interaction: 
The professional advisory committee is intended to provide a forum for development of integrated care planning. So, for instance, if we are looking at protocols for care of patients with chemical dependency we would expect social workers, physicians, nurses to be involved in the care of those patients. And so we would bring issues related to that, or development protocols, to this professional advisory committee for review.

The term "integrated," as used in the excerpt above, signals management's intent that a multidisciplinary collaboration would emerge in the new design based on collective professional accountability.

\section{Implementing Program Management Structures}

The program management process adopted in this context was considered similar to the product-line management system in the United States. The officials argued, however, that the Canadian model was unique in several respects (Shortell and Kaluzny 2000). First, they pointed out that they were dealing with change in a heavily unionized environment. Second, they wanted to distance their system from the American approach of profit-oriented managed care. Third, discipline-specific issues were fought for by nursing and other professional groups and were retained as a focus in the new structure. These three components are elaborated in the following subsections.

\section{Unionized environment}

The changes required by program management were negotiated in a heavily unionized environment. Negotiation between the employers and the union occurred at each stage of development and implementation. Unions are concerned with supporting and advocating for members' employment rights; it therefore follows that when changes in the workplace are initiated, unions have a role in ensuring that their members are not disadvantaged (Homes 2003). Specifically, the unions were concerned about redundancies, changes to the complexity of workloads and possible adverse impacts on client services (Homes 2003). LD explained that

... the only way you can downsize in this particular environment is through retirement. People just say, Oh, I'm quitting! And, I've had enough! And that's the only way you can downsize! And that's nursing, that's clerks, that's anybody who works in healthcare. So it's a very difficult environment to make any changes in!

The Canadian unionized environment is seen by CJ and LD as very different from the US healthcare environment. In Canada, they argued, adjustments to human resource personnel were more difficult to achieve. $\mathrm{LD}$ wanted to make changes more quickly but understood the constraints and politics of unionism, and was 
pleased that she had managed to implement changes despite the difficulties of a unionized environment. As a manager, she believed that progress had been hindered and delayed by the unions.

IP suggested that the staff nurses wouldn't take up autonomous roles or show creative potential because of the constraints imposed by unionism on the organizational setting. While the shift in nursing education from hospital-based training to the higher-education setting should bode well for professional nursing practice, at least in theory (Hood and Leddy 2003), IP suggested, somewhat regretfully, that the hospital organizational setting itself hasn't changed:

We moved professional nurses back into hospital settings and didn't change the hospital setting. The hospital settings prior to that had been staffed by students, and what we've done is treat professional nurses, who supposedly are independent autonomous practitioners, as if they were learners.

Following widespread bed reductions in acute health services, the challenge for officials was to introduce measures to make healthcare provision more cost effective that were consonant with union policies.

\section{Not in the business of healthcare}

LD emphasized that the approach to change adopted by the provincial health services organizations differed from the business approach of the American system: "I mean, we're not a business ... [not] like the American system at all. Beds are not filled to generate revenue, that is not an issue." The emphasis, she suggested, was on the provision of quality care for those who most need it, within the constraints of available resources:

... there is an emphasis here to get people out, patients out, because we're very limited in number of beds. And if you're not getting them out, you're not getting them in. And there certainly is a drive [to get them out]! But it's really a drive in terms of effective and efficient use of the resources; it's not an effort to make more money. So our drivers aren't necessarily the same drivers.

According to CJ, organizational officials looked at the US patient-focused care model four years earlier and selected aspects that might work or that matched their approach:

Some of the things we were already doing, and other things we thought might have some merit, and still other things we decided weren't practical or didn't match our philosophy. Some of the things we were already doing. 
HA acknowledged the influence of the US system but indicated the need to consider other options:

And so many of these new systems that are emerging from the States tend to be driven by a real need to be cost effective, and trying to streamline their standardized care in some way and to force collaboration between disciplines that haven't necessarily been very collaborative. But whether it's the right approach, or whether it should be only seen as a strategy rather than adopted as "the" pathway to get to Nirvana is a whole other thing.

\section{Redefining clinical operations within program structures}

One method used to encourage collaboration across disciplines was to move the budgets for individual professional disciplines away from centralized control in traditional departments and into "clinical business units" (programs). This process is similar to that of program budgeting and managerial analysis as discussed by Mooney (in Clinton 2004: 121-41), who stated “... the future is uncertain. Decisions have to be made about how to use resources wisely." BT argued that the mechanisms for change were created within the clinical operations themselves:

We hope to shift the emphasis from a manager of physiotherapy, or a manager of pharmacy, over to running the day-to-day activities in their department, to having a manager of the spinal cord unit, or a manager of an extended care unit, and actually coordinating the care of all of the professionals in that unit.

The change of emphasis - from management by traditional departmental structures to management by program units - altered the former reporting lines for discipline-specific healthcare professionals. The program model incorporated multidisciplinary practitioners into a "team" - a significant change from the previous (functional) model, in which the reporting lines operated across the specific disciplines. CJ alleged that discipline-specific reporting lines were maintained in the restructuring - an approach that he considered distinguished his organization's structure from its American counterparts. He argued that the difference related to maintaining two streams of authority:

What's been very important for us to do here is to identify two streams of responsibility and authority. One has been for resource management and provision of direct clinical care, and that's where we're saying it's gonna be a multidisciplinary team. The manager will be the best person suited for the position, and all the care providers in the particular clinical unit will work as a unit, as a team. The other stream has been the professional development, professional department stream, and there we're saying there is still a 
role for a department head or a professional practice leader, as we're calling them. It may not be a full-time job, it may be someone who does it two or three afternoons a week and the rest of the time they're doing clinical work or some other administrative duty. But there is a role, and that will encompass things such as setting standards for hiring, participating with the manager of the unit, setting standards for evaluation for the professional component of evaluation.

CJ did not see the two streams of authority as counterproductive or tending to confusion. He argued that the professional department head may define, for example, the forms that the practice of physiotherapy should take in this hospital. At the same time, another person - the unit manager - would manage the day-to-day work performed by the staff.

What emerged in practice was dual reporting mechanisms or reporting lines: one for professional discipline-specific issues and another for professional team responsibilities for the delivery of patient-centred care. CJ did not believe that the dual reporting lines gave rise to inefficiencies; rather, he considered that they resulted in improved practice.

YP, a program director, explained her dual reporting lines under program management:

I report not only to our vice-president [patient services] about patientcentred care and standards and the disciplines, but I also report to the vicepresident [operations] for the business program, proposals and development. Staff nurses report not only to a manager for the program and for all the interdisciplinary team about patient care, but they also report through their manager in nursing through to the nursing practice council for standards as a discipline.

As a consequence of dual reporting lines, YP believed that the specific needs of the discipline were not neglected within the teams that provide patient-centred care within a unit. Nursing's specific discipline needs were met, according to YP, in two ways:

One is I'd have a group going with the managers of nursing and the educators and we look at certain policies, procedures, standards, issues from a larger or external point of view that is going to impact on us internally. And then the nursing managers and educators meet with the staff nurses to try to figure out where we're at and where we should be. And we link that in with our representative who's on the nursing practice council, and then the 
nursing practice council looks at the nursing standards for the hospital. So it's not just psych, there's just one representative there for psychiatry. It's all like that across the programs.

The restructuring along program lines, in which a blend of disciplines must report to a unit-based program director, created uncertainty about which professional discipline should hold key managerial positions. Similar concerns have been reported by Clinton (2004) and Hibberd and Smith (1999), who argue that interand intraprofessional rivalry are factors affecting healthcare organizational reform.

Nurses in the organization, according to YP, retained a significant senior role. She confided that questions concerning the strategic use of staffing resources within program management continued to be raised, particularly in relation to appointing nurses as coordinators of care within multidisciplinary teams.

VP acknowledged that the new organizational structures provoked resistance:

It has been tremendous. We've been struggling with this for years. Part of the resistance is because the other disciplines resent the nurses' role. And they resent the role that nursing has taken in dominating the team, dominating resource allocation.

\section{Renewing the focus on multidisciplinary teams}

The redesign of clinical operations, through financial and organizational mechanisms, necessitated the redesign of work practices and reconfiguration of the multidisciplinary team. The introduction of program management was received with varying degrees of support. According to Daly et al. (2004), the organizational issues that emerged concerning professional power and control were neither new nor uncommon in complex professional bureaucracies. The dynamic nature of the "team structure" within a program management approach was highlighted by the officials as a causative factor for staff resistance (Hood and Leddy 2003).

External to the organizational environment, the "team" agenda was being debated in a multidisciplinary review of domains of expertise and scope of professional practice. A Health Professional Council was conducting a review of barriers to interdisciplinary practice that existed in provincial regulatory frameworks (Hibberd and Smith 1999).

IP and HA were involved in the review as representatives of nursing. IP explained that the review - which was expected to clarify elements of a health profession's particular scope of practice - was the forum in which health professionals vied for elements that they considered as belonging to their practice area. The view held by 
the provincial government was that the health professions reserve exclusive areas of practice simply to enhance professional status and control.

HA pointed to legislative barriers that made the introduction of "managed care" more difficult in Canada than in the United States. According to her, professional restructuring, which she viewed as synonymous with "managed care," was not as easily achieved in Canadian as in American hospitals. HA argued that the scope of practice of Canadian nurses was more regulated than that of their US counterparts, and that there are also differences in the regulation of nursing practice among provinces and territories. Senior nurses, she maintained, are currently unable to admit or discharge patients or refer for specialist procedures. On the other hand, she claimed, nurses in some practice contexts carry out activities, in the absence of medical direction, that are unsanctioned by any legal framework.

HA suggested that such legislative barriers prevent nurses and possibly other professionals from performing work for which, she considers, they have expertise. The barriers she refers to constrain and limit nursing's ability to broaden its scope of practice (Daly et al. 2004; Crisp and Taylor 2005). One suggested motive for limiting nurses' activities is the arrogation by other professions of some domains of nursing practice. If this is so, then the review might be seen as having evolved from an application of provincial competition policy.

\section{Resource Utilization Review}

Officials are progressively introducing strategies and tools into program structures to improve resource utilization. Cost-cutting measures in the mid-1990s resulted in pressure for increased efficiencies in patient care (Stingl and Wilson 1996). A major strategy introduced was to shorten lengths of stay for hospitalized patients. While shorter lengths of stay help cut costs, it is argued that this strategy merely amounts to cost shifting (Shortell and Kaluzny 2000). CJ explained that cost-cutting in one area may amount to cost increases in another:

Our length of stay drops every year by five to 10 percent. Year after year, it keeps going down! People say, well, when is it gonna end! The length of stay drops, we close the beds, we look after the same number of patients, and we lay off staff. Every year the length of stay drops, obviously the patients remaining in hospital are sicker and they're going home sicker. In a way it's cost shifting to the home care agencies, to family members and to the patients themselves. But it means that we're able to focus our resources where they're most needed.

CJ believed that shortened lengths of stay distribute resources to "those in need." 
Strategies for improving resource utilization described by organizational officials included benchmarking, the integration of patient records, improved methods of documentation including exception-based charting, multiskilling, eliminating non-nursing duties, exploring staffing ratios, use of clinical pathways and nursing care plans, case management, unit-based developments and investing in clinical nurse specialists (Hibberd and Smith 1999; Clinton 2004). Each of these strategies is described more fully in the subsections below.

\section{Benchmarking}

Benchmarking is "the process of establishing operating targets based on the leading performance standards for the industry" (Shortell and Kaluzny 2000). CJ explained that "benchmarking" against other health providers' practices has been an important method for determining effectiveness. He described comparing

the hours of nursing care, physiotherapy, whatever, per patient at our hospital with those in other hospitals. We hired a consultant firm to use their database of a variety of hospitals so we could actually compare. We used that then as a basis for comparison. How are you able to achieve reduced hours of care for the manager in vascular surgery? We phoned her counterpart at a private hospital. How's this work in your hospital?

The engagement of consultant firms was an approach CJ introduced. Consultants, he suggested, were necessary because the organization felt it did not have the required expertise (Hood and Leddy 2003). CJ stated that he engaged consultants in ways that were different from the approach used in the United States, where consultants are given greater influence over strategic change. He pointed out that consultants in Canada are hired to carry out work determined by the organization.

\section{Exception-based charting}

Exception-based charting, a new form of documentation for nursing practice, involves documenting only exceptions to normal procedures. The intent of "charting by exception" is to reduce repetition and time spent in charting (Crisp and Taylor 2005: 476). CJ claimed that

a standard of care defines many procedures within the unit and people only chart the exceptions to that. So we've tried to eliminate all the garbage in the nurses' notes with the exception-based chart. That was a fair struggle. There was a lot of resistance among nurses who didn't want to give up their compulsive desire to write down absolutely everything they had done on a shift for a particular patient regardless of whether anyone ever read the notes. 
The introduction of nursing charts, which are exception-based, was a slow process, suggested LD:

... unfortunately, we're still somewhat slow in changing our charting practices from narrative to anything other than narrative. We've been slow in that and we're really working quite hard at.

In reducing unnecessary reporting, exception-based charting was seen to increase the time available for care. CJ and LD believed that more efficient charting is linked to "standards" and "better practice," a position supported by Hood and Leddy (2003).

Integrating nursing care plansIntegrating nursing care plans, according to LD, was another battle. Each department had developed individual plans without coordinating and consulting with other departments and consolidating resources. LD noted that the tendency for various departments to develop different plans, rather than a single overall plan, proved an ongoing problem:

And I think the other thing that we have done in our organization is we have a lot of creators, but we don't have coordinators! If I ask for the asthma care plan, I'll get about five of 'em! This unit did it, this unit did it and this unit did it. Everyone's got a standard care plan, and it was somewhat ridiculous! So we have been busy with inventing, but not in terms of coordinating those activities.

\section{Eliminating non-nursing duties}

Work had been undertaken globally within health services organizations to reconfigure tasks performed by nurses (Daly et al. 2004; Crisp and Taylor 2005; Tabner 2005); Hibberd and Smith 1999). The reorganization of workload was justified on the basis that the activities that nurses engaged in were "appropriate" and reduced or eliminated time involved in non-nursing duties. According to CJ, these included

having nurses passing out trays, ordering medications, hauling bags of garbage and linen, restocking carts and supply areas, cleaning. We'd taken a lot of that out over the years anyway, and that was a very important issue in terms of our development of nurses' sense of their influence being based in their practice. We're looking further at skill mix but we've done a lot in that regard.

\section{Staffing skill mix}

As a strategy to contain costs, many hospitals in Canada adopted higher ratios of LPNs (licensed practical nurses) to RNs (registered nurses). LD expressed delight that her program (paediatrics) retained its existing "all-RN" workforce. She stated 
that all-RN staffing on patient care units is becoming less common. She regarded the paediatric program as having special needs, and argued that only RNs could deliver the appropriate level of care:

It does take more professionals to provide paediatric care. Paediatric beds are the most expensive ones. It's the level of dependency with the applications and staffing ratios and all those kinds of things.

IP argued that higher LPN-to-RN ratios have not reduced costs:

One facility in another province decided that because of the pressures that were going on, they were going to "all-RN" staff, which they didn't have before. And it will be interesting to see the comparisons. But so far their costs are holding equivalent - which, of course, is what's driving [program management] in the first place.

According to a scenario reported by IP, LPNs as a group are unable to cope, or cope fully, with the care demands required by patients. As LPNs are accountable to and are managed by RNs, IP predicted that this situation will place pressure on the RNs who have ultimate responsibility for quality of care. HA predicted that "hospitals will increasingly [become] intensive care units" for higher-acuity patients as more and more care is offered in the community.

Increasing the ratio of LPNs to RNs would enable short-term savings on salary costs, HA suggested. However, with the complexities associated with increasing acuity in the acute care hospital sector, this strategy may ultimately result in no savings at all:

If we have hospitals becoming intensive care units and the defined role for practical nurses is to work with stable, predictable people, ... [there's] no place for [LPNs] in hospitals, unless they are assigned to the nurse to be her auxiliary pair of hands and not assigned to patients. And then we have to teach nurses how to use them effectively as auxiliary hands, too, because they have not been well taught about how to delegate and supervise others.

HA reflected critically on new work redesign methods, associated with productline management, that involve changes in skill mix. She suggested that the focus on improving productivity and cutting labour costs does not lead to improved quality, or to worker or consumer satisfaction:

The rejigging of nursing tasks operates in terms of the "big time factor," and of course time is money. And as soon as we get to the time/motion stud- 
ies that a lot of our workload tools are at least generally based on (some of them have other types of built-in factors) and look at the performance of task, what you're doing is measuring the most obvious or superficial, and also assuming that there is some time factor that can be controlled in that process.

HA mentioned that there has been very little research or data supporting the claim that patient outcomes vary with different forms of patient care delivery systems.

Despite the predilections held by HA and IP regarding the benefits of all-RN staffing, CJ had different ideas about staffing in the context of program management. He emphasized that baccalaureate education for staff nurses has changed nurses' expectations of what they want to do and achieve. Nurses, he claimed, want a wider role in health promotion and other activities:

We are looking further at skill mix, as we have emphasized baccalaureate education for staff nurses here as well as managers and above. But as we've done that, then the expectations are changing for what nurses want to do. In fact, they want more of a role in health promotion and other activities. It doesn't make a lot of sense to have someone who has those kinds of expectations, and who is paid relatively well, to have those people spending a lot of time doing routine care that could be carried out by patient care aides and others.

CJ planned to explore multiskilling further, arguing that he has not considered the role of assistant workers in patient care units:

Over time things have changed, and now we're seeing - as we have got a more educated workforce - sicker patients increase cost pressure. It's no longer appropriate in all areas to use that delivery system, and that's why we're looking at more of a skill mix.

HA prefaced her position by stating that assistant workers need to be assigned to the nurse and not to patients. She felt that assistant workers should focus on doing things that the nurse determines. She reported that a nursing professional association has developed a document to facilitate nurses' roles in delegation.

The issues concerning staffing and skill mix were of concern to the participants. The data indicated that the officials perceived nursing staff to be reluctant to delegate and attributed this deficit to poorly developed management skills, a conclusion supported by Hibberd and Smith (1999), Daly et al. (2004) and Hood and Leddy (2003). 


\section{Clinical pathways, case management}

IP identified a strong association between managed care and total quality management (TQM) in the strategies, tools and processes required for the development of clinical pathways. Clinical pathways has been defined as "a multidisciplinary treatment plan that sequences clinical interventions over a projected length of stay or a projected time frame for specific case types" (Crisp and Taylor 2005: 35). HA stated that clinical pathways are useful, but are time consuming and expensive to develop and implement:

They provide a wonderful base for evaluating cases that don't map out exactly. You can easily look at those cases and evaluate what was different about them. It's a wonderful tool for quality management.

As a resource strategy, clinical pathways has been credited with improving system efficiency (Crisp and Taylor 2005). However, IP suggested this strategy potentially impedes nurses' capacity to individualize care:

... the whole notion of managed care comes into that, and the whole notion of whether managed care and the strategies that we use to implement it, like care maps, are going to drive care, and supersede nurses being able to individualize their care.

As part of resource utilization review initiatives, health services organizations may develop clinical pathways in, for example, high resource usage areas where there are large volumes and high costs. These areas include hip reconstruction, cardiac care, cardiac surgery and bone marrow transplants. CJ conceded that the process of developing clinical pathways has valuable effects on coordinating interactions across the multidisciplinary teams:

I think the most important part is the process of having people sit down and work together, to generate a multidisciplinary approach to care. Out of that, then, I think there's a lot of spillover effect, trickle-down effect, upon the other things that they do.

LD differentiated clinical pathways from nursing care plans, arguing that nursing care plans are more specific to nursing. She believed that clinical pathways do not replace a nursing care plan:

Without nursing care plans, it would be more difficult to do clinical pathways, because you wouldn't have a nursing perspective. My understanding of clinical pathways is that they really are a pathway of care that everyone provides as a patient walks through the door, leaves and then is followed up. 
And ... it's everybody's plan; it's not just any professional group's.

Other techniques were reported to have been developed to manage clinical resources efficiently. Clinical guidelines were highlighted by CJ as a method of improving the efficiency and standardization of practice (Tabner 2005). HA referred to case management as another form of delivery system that is grounded in clinical practice and involves the development of clinical pathways:

Case management was looked at as a very positive thing, but as extremely expensive and time consuming to implement. Otherwise, I think there would be more organizations on this bandwagon.

\section{Unit-based developments}

LD described new unit-based development strategies. She claimed that by decentralizing casual staff employment to the unit level, unnecessary numbers of supervisors were eliminated. LD acknowledged, however, that the organization had to provide a method of supervision to replace the existent cost-inefficient service. She described an on-call system that rostered a senior nurse as supervisor covering a 24-hour period seven days a week. Backup for the on-call senior nurse was provided by the vice-president and LD, and a resource manual was developed that supported these changes.

LD reported that she undertook a review and modification of the policy and procedure manuals. She stated the process was informed by current evidence in keeping with recommendations for accreditation that occurred every three years:

It's been a tough haul [cleaning up the manuals] because nursing is steeped in tradition - a lot of sacred cows! - and many of the policies and procedures in our manuals were built and made in the early 1980s, and that's pretty bad for a professional practice!

The review process was challenging, suggested LD:

We've got people who are more enthused about the whole process of looking at the literature and developing the procedures and policies. It's really steeped in research versus you take a temperature at four o'clock.... I remember the old days!

\section{Clinical nurse specialists}

The officials identified investment in employing clinical nurse specialists (CNSs) as a productive organizational reform strategy. CNSs have been described as "highly skilled clinical experts in a specialized area of nursing practice" (Hood and Leddy 
2003: 145). CJ stated that there were "about a dozen clinical nurse specialists ... who have hospital-wide responsibilities; some of them are more hospital focused and some are more unit focused." He stated that CNSs are distinguished from other care providers because they are not unit based, but extend across departments:

In our particular organization we have a lot of general duties staff nurses. We've got a thousand nurses here! And we have only a few nurse clinicians [consultants], and only a very few clinical nurse specialists. I think we have four clinical nurse specialists and only a handful of nurse clinicians. So there really aren't a lot of folks who become advanced practitioners. But they have a leadership role in terms of clinical leadership around helping other staff with unique problems that they come up to. For example, if there's a child in the ward with a feeding problem relating to cleft palate, then the nurse clinician in that program would be assisting unit staff with feeding issues.

According to HA, clinical nurse specialists had more power than many other hospital personnel and exhibited assertive and determined behaviour in contrast to other nurses:

They're seen as such clinically competent people. When they say "taa-taa" the rest of the team sits up and takes notice. It's almost like the power physicians have held on to for years with the Boards of Directors and the community and the public and patients - who think whatever the doctors say must be absolute gospel. Well, that's the same light that these clinical specialists are seen in, in organizations.

HA noticed that the role of CNSs became operationalized. The CNSs were responsible for the coordination of care and case management functions. She considered that many nurses have the potential to become CNSs; however, it has been suggested that their knowledge and skill is neither acknowledged nor valued by the healthcare system (Hibberd and Smith 1999).

\section{Discussion}

Canadian officials have adopted the term "program management" to denote a new form of governance in health services organizations in which clinical operations evolve within a changed structural configuration (Hibberd and Smith 1999). Program management facilitates change through improved networks of communication and decision-making (Clinton 2004; Shortell and Kaluzny 2000). The main drive towards program management stemmed from provincial governments' implementation of economic reform. 
Findings from this study revealed a complex interplay of institutional, professional and disciplinary processes and tensions that officials attributed to the changing organizational configurations of program management. The data indicated a diversity of opinions, positions and strategies used by these healthcare managers and nursing professionals in implementing reforms. The study highlighted the officials' tendency to speak the language of reform with regard to the organization and delivery of clinical care.

Conflict was evident between unions and administrators regarding the implementation of program management. Unions' primary concern is to preserve and enhance working conditions, while organizational administrators focus on advancing agendas that meet employer or group needs. CJ and LD voiced frustration that the unions' efforts to protect their members hampered the progress of change.

Elements of professional solidarity emerged, with nurses adopting a proactive stance and maintaining a discipline-specific focus during restructuring. Officials who identified with nurses recognized that program management had implications for nursing practice and education. Some voiced high hopes for the future of clinical nurse specialists as authorities in defining the parameters of nursing care, setting standards and invigilating care. Others perceived that leadership in nursing practice was under threat, suggesting that nurses should be more proactive in these developments rather than become the victims - or indeed, the agents - of health economists.

Officials perceived program management to derive from the US model of managed care (Shortell and Kaluzny 2000). While they accepted that there were similarities with the American product-line management approach, they argued that their model was different. They considered that because the "drivers" are dissimilar, the practice that has evolved in the Canadian context is quite different. Officials maximized their efforts to develop cost-effective care in a more business-oriented and competitive environment. They believed that patient care delivery systems should change. "Managed care" was not a key term in the discourse of these officials, who rejected the commercial emphasis associated with the profit-driven model of American-style managed care. They identified "patient-centred care" as a principal determinant in the operation of their system of program management.

Program management has incorporated diverse measures to make care provision cost effective and efficient. The officials in our study saw two important steps as central to program management. First, reconfiguration of formerly disciplinespecific departments into programs progressively enhanced multidisciplinary teamwork. Second, the multidisciplinary focus strengthened the professional practice roles that evolved, placing the patient (rather than the professional discipline) at the centre of care. 


\section{Conclusion}

Program management is an important step in health services governance that emphasizes resource utilization or resource management. It can be viewed as a change or strategic shift that promotes multidisciplinary practice as a new approach to patient-centred care. The underlying assumption is that the relationship between the various professionals who provide clinical services, and their respective tasks and responsibilities, should change (Hibberd and Smith 1999; Globerman et al. 2002; Clinton 2004).

Program management creates the basis for examining and modifying infrastructure and processes as they affect practice. The officials in this study described their operations and the various measures and steps that were taken for strategic, business, practical, economic and professional reasons, which reflect the literature (Hibberd and Smith 1999: 150-52). They identified strategies that evolved from resource management, including benchmarking, integration of patient records, improved documentation, multiskilling, "investing" in clinical nurse specialists and eliminating non-nursing duties from nurses’ practice.

Some of the officials interviewed believed that the structural changes implemented were beneficial. They agreed that these improved links between management, professionals and patients through noncompetitive alliances. However, some officials were not convinced that program management was the most useful approach for professional nursing practice.

As an organizational reform, program management emerged from the intensely competitive market upheavals of the 1990s (Hibberd and Smith 1999; Clinton 2004; Hood and Leddy 2003). Canadian officials, in this healthcare setting, have dealt with the organization and delivery of clinical care in diverse ways in response to the interplay of policy and practice.

\section{Acknowledgments}

Special thanks to Mary-Ellen Purkis, Lawrence Angus, Michael O'Loghlen and Sonia Allen for making valuable comments and suggestions on drafts of this manuscript. I thank the participants who so generously contributed their time, ideas and guidance for this study.

Correspondence may be addressed to: Dr. Liza Heslop, Centre for Health Services Operations Management, Faculty of Medicine, Nursing and Health Sciences, Monash University, Victoria, Australia; email: liza.heslop@med.monash.edu.au.

\section{References}

Brink, P. and M. Wood, eds. 1998. Advanced Design in Nursing Research. Thousand Oaks, CA: Sage.

Clinton, M., ed. 2004. Management in the Australian Health Care Industry (3rd ed.).
Frenchs Forest, NSW: Pearson Education Australia.

Crisp, J. and C. Taylor. 2005. Potter and Perry's Fundamentals of Nursing (2nd ed.). Sydney, Australia: Elsevier. 


\begin{tabular}{|c|c|}
\hline Daly, J., S. Speedy and D. Jackson. 2004. Nursing & \multirow{5}{*}{$\begin{array}{l}\text { Kieser, D. and D. Wilson. 1995. “The Canadian } \\
\text { Health Care System: Trends, Issues and } \\
\text { Challenges.” In D. Wilson, ed., The Canadian } \\
\text { Health Care System (pp. 87-96). Edmonton: } \\
\text { Author. Retrieved May 2, 2005. <http://www. } \\
\text { ualberta.ca/ dmwilson/dw3.html>. }\end{array}$} \\
\hline Leadership. Marrickville, NSW: Elsevier. & \\
\hline Globerman, J., J. White and G. McDonald. & \\
\hline 2002. "Social Work in Restructuring Hospitals: & \\
\hline $\begin{array}{l}\text { Program Management Five Years Later." Health } \\
\text { and Social Work 27(4): } 274-84 .\end{array}$ & \\
\hline \multirow{6}{*}{$\begin{array}{l}\text { Hibberd, J.M. and D.L. Smith. 1999. Nursing } \\
\text { Management in Canada (2nd ed.). Toronto: W.B. } \\
\text { Saunders. } \\
\text { Homes, N.H., ed. 2003. Five Keys to Successful } \\
\text { Nursing Management. Philadelphia: Lippincott. } \\
\text { Hood, L.J. and S.K. Leddy. 2003. Conceptual } \\
\text { Bases of Professional Nursing (5th ed.). } \\
\text { Philadelphia: Lippincott. }\end{array}$} & Shortell, S.M. and A.D. Kaluzny. 2000. Health \\
\hline & \\
\hline & \\
\hline & \multirow{2}{*}{$\begin{array}{l}\text { Stingl, M. and D. Wilson, eds. 1996. Efficiency } \\
\text { vs. Equality: Health Reform in Canada. Halifax: } \\
\text { Fernwood. }\end{array}$} \\
\hline & \\
\hline & $\begin{array}{l}\text { Yin, R. 1993. Applications of Case Study } \\
\text { Research. Newbury Park, CA: Sage. }\end{array}$ \\
\hline
\end{tabular}

